\title{
EVALUASI STANDAR PELAYANAN MINIMAL LAMA WAKTU TUNGGU PELAYANAN PENDAFTARAN PASIEN RAWAT JALAN DI KLINIK BINTANG MEDITAMA
}

\author{
Putri Wardani \\ Politeknik Piksi Ganesha Bandung, Indonesia \\ wardani_putri20@yahoo.co.id
}

Received: 08-09-2021

Revised : 16-11-2021

Accepted: 18-11-2021

\begin{abstract}
Abstrak
Latar Belakang: Sudah timbul bermacam kasus tentang standar pelayanan minimun, salah satunya merupakan lama waktu tunggu pelayanan rawat jalan pada bagian registrasi. Waktu tunggu yang lama ialah salah satu perihal yang dapat menimbulkan ketidakpuasan pasien. Apabila waktu tunggu lama dapat mengurangi kenyamanan pasien.
\end{abstract}

Tujuan: Mengenali lama rata-rata waktu tunggun pelayanan registrasi pasien rawat jalan untuk dijadikan bahan penilaian agar kedepannya pelayanan di Klink Bintang Meditama khususnya pada registrasi pasien rawat jalan mampu ditingkatkan lagi serta sesuai dengan Standar Pelayanan Minimun

Metode: Tipe riset deskriptif (riset survey) di tempat registrasi penderita rawat jalan, serta memakai Metode purposive sampling ialah pengambilan ilustrasi bersumber pada kriteria yang diresmikan oleh periset ialah penderita rawat jalur baru serta lama.

Hasil: Registrasi penderita rawat jalan pada penderita baru ialah 12 menit serta pada penderita lama ialah 06 menit. Dengan demikian pelayanan di tempat registrasi penderita rawat jalan masih belum sesuai dengan Standar Pelayanan Minimun yang diresmikan di Klinik tersebut dianjurkan untuk petugas hendaknya lebih mencermati lamanya waktu tunggu di bagian registrasi rawat jalan dengan bekerja lebih kilat serta cermat sesuai dengan SOP supaya tercapainya pelayanan waktu tunggu registrasi rawat jalan yang sesuai dengan SPM yang telah didetetapkan oleh Klinik tersebut.

Kesimpulan: Berdasarkan survey kategori waktu tunggu pelayanan pendaftaran rawat jalan Klinik Bintang Meditama diketahui saat ini belum berjalan dengan baik dan belum optimal, Penulis berpendapat penelitian di klinik tersebut belum dilakukan.

Kata kunci: standar pelayanan minimal; waktu tunggu; tempat pendaftaran pasien rawat jalan.

\footnotetext{
Abstract

Background: There have been various cases about minimun service standards, one of which is the length of waiting time for outpatient services in the registration section. Long
} 
waiting times are one of the things that can cause patient dissatisfaction. If the waiting time is long, it can reduce the comfort of the patient.

Objective: Recognize the length of the average waiting time for outpatient registration services to be used as assessment material so that in the future services at Klink Bintang Meditama, especially in outpatient registration can be improved again and in accordance with minimun service standards.

Methods: Descriptive research type (research survey) at the registration of outpatient patients, and using the purposive sampling method is the collection of illustrations sourced on the criteria inaugurated by researchers are new and old outpatient patients.

Results: Outpatient registration services in new patients is 12 minutes and in old patients is 06 minutes. Thus, the service at the outpatient patient registration place is still not in accordance with the Minimun Service Standards inaugurated at the Clinic it is recommended that officers should pay more attention registration section by working more quickly and carefully SOP so that the achievement of outpatient registration waiting time services SPM that established by the Clinic.

Conclusion: Based on a survey of the waiting time category of outpatient registration services Bintang Meditama Clinic is known to be currently not running well and has not been optimal, the author argues that the research at the clinic has not been done.

Keywords: minimum service standard; waiting time; outpatient registration.

*Correspondent Author: Putri Wardani Email: wardani_putri20@yahoo.co.id

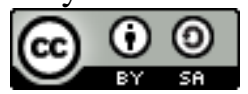

\section{PENDAHULUAN}

Rumah sakit merupakan sarana kesehatan yang menyelenggarakan pelayanan kesehatan perorangan meliputi pelayanan promotif, preventif, kuratif dan rehabilitatif yang menyediakan pelayanan rawat inap, rawat jalan, dan gawat darurat (RI, 2008). Rumah sakit, klinik atau balai kesehatan dan instansi lainnya yang beranjak pada pelayanan kesehatan salah satu bentuk pelayanan pada bidang kesehatan yaitu melayani kebutuhan pasien secara profesional, berdikari dan bertanggung jawab tanpa mengabaikan hak dan kewajibannya (Sinadia, Kimbal, dan Undap, 2018).

Konsep pembangunan kesehatan, dibutuhkan bahwa klinik sebagai sentra pembangunan kesehatan pada daerahnya, Klinik adalah salah satu pelayanan kesehatan yang wajib menaruh pelayanan yang baik, berdasarkan pelayanan yang diberikan, dari Keputusan Menteri Kesehatan Republik Indonesia No.028/MENKES/PER/I/2011. Klinik adalah fasilitas pelayanan kesehatan yang menyelenggarakan pelayanan kesehatan perorangan yang menyediakan pelayanan medis dasar dan/atau spesialitik, diselenggarakan 
oleh lebih dari satu jenis tenaga kesehatan dan dipimpin oleh seorang tenaga medis (Menkes, 2011).

Instalasi Rawat Jalan (IRJ) merupakan unit fungsional yang menanganai penerimaan pasien di rumah sakit, baik yang akan berobat jalan maupun yang akan dirawat di rumah sakit. Pemberian pelayanan di instalasi rawat jalan pertama kali dilakukan TPP (tempat pendaftaran pasien), yang dikelola oleh bagian Rekam Medis Rawat Jalan (Depkes, 2009). Mengenai pelayanan medis pada semua forum atau instansi kesehatan, terlepas berdasarkan adanya pelaksanaan pelayanan minimal. Standar Pelayanan Minimal adalah ketentuan tentang jenis dan mutu pelayanan dasar yang merupakan urusan wajib daerah yang berhak diperoleh oleh setiap warga secara minimal dan juga merupakan spesifikasi teknis tentang tolak ukur pelayanan minimal yang diberikan oleh badan layanan umum kepada masyarakat (Permenkes, 2008b).

Pasien akan menganggap pelayanan kesehatan kurang baik apabila tidak mendapatkan pelayanan kesehatan yang tidak maksimal dan antrian lama, petugas kesehatan tidak ramah meskipun profesional. Bila waktu tunggu di pelayanan pendaftaran rawat jalan lama maka hal tersebut akan mengurangi kenyamanan pasien dan berpengaruh pada citra Klinik yang dapat mempengaruhi utilitas pasien dimasa mendatang (Hani, 2013). Waktu tunggu di Indonesia ditetapkan oleh kementrian kesehatan (kemenkes) melalui standar pelayanan minimal berdasarkan pada pelayanan rawat jalan indikator waktu tunggu pelayanan pasien rawat jalan yaitu 60 menit dimulai dari pasien mendaftar sampai dilayani oleh dokter (Permenkes, 2008a). Kepuasan adalah perasaan senang atau kecewa seseorang yang muncul setelah membandingkan antara persepsi atau kesannya terhadap kinerja atau hasil suatu produk dengan harapan-harapannya (Nurfadillah \& Setiatin, 2021).

Kepuasan pasien dapat membentuk persepsi dan selanjutnya dapat memposisikan produk perusahaan di mata pasiennya (Kusumaningtyas, 2016). Pasien yang tidak puas akan mencari pelayanan medis lain yang dapat memberikan nilai memuaskan. Kepuasan pasien adalah respons evaluatif, afektif atau emosional yang terkait dengan mutu pelayanan yang diberikan rumah sakit serta harapan pasien terhadap pelayanan tersebut (Mumu,

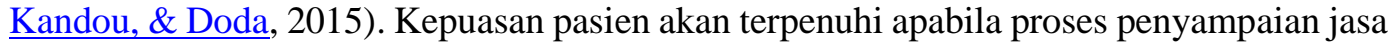
dari pembeli jasa kepada pasien sesuai dengan apa yang dipersepsikan pelanggan. Presepsi ini dipengaruhi oleh faktor subyektifitas yang dapat membuat perbedaan persepsi atau kesenjangan antara pelanggan dan pemberi jasa (Hafizurrachman, 2004)

Sehingga para pengguna jasa kesehatan bisa terlayani secara optimal dan adanya kepuasan. Salah satu pelayanan di klinik yang diharapkan memenuhi standar pelayanan minimal adalah pelayanan pendaftaran pasien rawat jalan. Pelayanan Rawat Jalan yaitu rangkaian aktivitas pelayanan medis yang berkaitan menggunakan aktivitas poliklinik atau ruang periksa., Pelayanan rawat jalan adalah layanan yang diberikan pada pasien yang berobat jalan dan tidak lebih dari 24 jam (Beatson et al., 2016).

Pemberian pelayanan pertama kali dilakukan pada loket pendaftaran, fungsi utama dari loket pendaftaran pasien itu sendiri yaitu sebagai tempat melayani pasien, baik itu pasien baru maupun pasien lama. Pelayanan pendaftaran pasien yaitu menjadi gerbang utama dalam menyambut kedatangan pasien (Tena, 2017). Tidak sedikit ada terjadi banyak sekali pertarungan mengenai standar pelayanan minimal banyak sekali unit pelayanan kesehatan, salah satunya yaitu saat tunggu pelayanan registrasi terhadap pasien rawat jalan.

Sebagaimana dalam penelitian yang dilakukan oleh Faik dan Ferdiansyah (2019) membuktikan bahwa homogen-homogen saat tunggu pelayanan registrasi pasien rawat jalan untuk pasien lama 8 menit 44 detik sedangkan homogen-homogen waktu tunggu untuk pasien baru 12 menit 40 detik saat registrasi pasien rawat jalan dan masih belum sesuai standar pelayanan minimal. Menurut (Komalasari, 2019) saat tunggu dapat diartikan menjadi orang-orang atau barang pada barisan yang sedang menunggu buat dilayani, kategori saat tunggu pada Indonesia ditetapkan oleh Kementerian Kesehatan (Kemenkes) melalui standar pelayanan minimal dari Kemenkes Nomor 129/Menkes/SK/II/2008. Waktu 
tunggu keliru mengakibatkan ketidakpuasan pasien, pada saat tunggu pasien mencerminkan bagaimana Klinik mengelola komponen pelayanan yang diadaptasi setiap harinya. Setiap puskesmas harus mengikuti standar pelayanan minimal saat tunggu (Permenkes, 2008c).

Kunjungan pasien yang semakin tinggi dan terjadi kepadatan jumlah antrian pada loket registrasi, hal ini akan berdampak dalam saat tunggu pasien, maka berdasarkan itu menggunakan adanya standar pelayanan minimal akan mengetahui berapa lama saat tunggu pelayanan registrasi pasien rawat jalan yang diberikan oleh petugas pada pasien lama ataupun pasien baru, dan diharapkan penelitian penilaian spm saat tunggu pelayanan registrasi pasien rawat jalan pada Klinik Bintang Meditama.

Maka dari itu akan bertujuan buat mengetahui berapa lama saat pasien lama juga pasien baru pada pelayanan registrasi pasien rawat jalan pada Klinik Bintang Meditama. Berdasarkan penelitian di atas, bahwasanya penting penelitian ini dibutuhkan untuk bisa menyebarkan ilmu pengetahuan menggunakan kebijakan dan taktik peningkatan kualitas pelayanan kesehatan khususnya dalam standar pelayanan minimal dan bisa berguna bagi masyarakat penerima layanan kesehatan supaya menerima pelayanan yang lebih baik.

\section{METODE PENELITIAN}

Metode penelitian yang dilakukan dalam penelitian ini yaitu metode deskriptif (penelitian survei) di tempat pendaftaran pasien rawat jalan di Klinik Bintang Meditama. Cara pengambilan sampel dengan menggunakan teknik purposive sampling. Kriteria yang ditetapkan oleh peneliti yaitu pasien rawat jalan baru dan pasien rawat jalan lama, karena pada penelitian ini populasi yang didapat sudah dapat diperkirakan selain itu juga objek yang diteliti sudah sangat spesifik yaitu pasien rawat jalan baru dan pasien rawat jalan lama baik itu peserta BPJS Kesehatan atau Non BPJS Kesehatan (Umum). Guna menghitung waktu peneliti menggunakan alat ukur stopwatch. Penelitian dilakukan pada bulan Mei 2021. Jumlah populasi yaitu sebanyak 2.300. Kemudian digunakan rumus slovin untuk menghitung jumlah sampel yang diperlukan dalam penelitian ini,

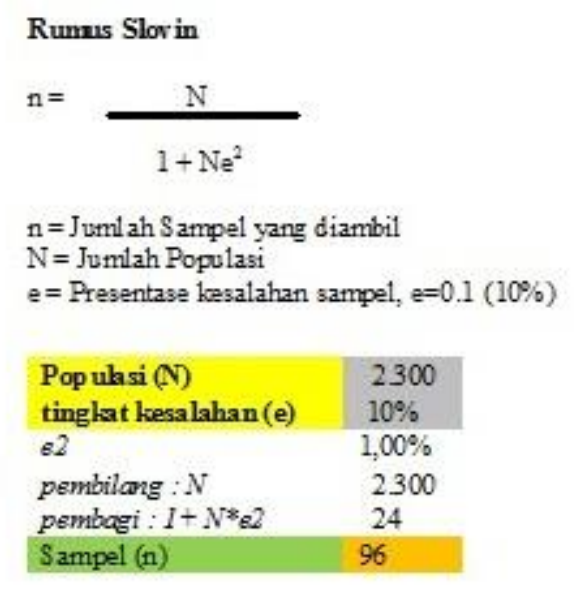

\section{Gambar 1. Rumus Slovin untuk menghitung sampel}

Berdasarkan hasil perhitungan tersebut maka sampel yang akan diambil yaitu sebanyak 96 pasien, 48 untuk pasien lama dan 48 untuk pasien baru yang berkunjung berobat ke Klinik Bintang Meditama. Penelitian dilakukan observasi secara langsung untuk mengaplikasikannya dengan cara peneliti mengukur waktu pasien pada saat dilayani di 
loket pendaftaran dengan menggunakan stopwatch, lalu ditulis pada form yang sudah disediakan oleh peneliti. Setelah data didapatkan peneliti mengolah data menggunakan microsoft excel untuk menghitung rata-rata lama lama waktu tunggu untuk pasien lama maupun pasien baru di Klinik Bintang Meditama, hasil dari rata-rata lama waktu tunggu ini akan dibandingkan dengan kriteria pelayanan yang sudah disesuaikan oleh Klinik Bintang Meditama dengan standar ketentuan yaitu untuk pasien lama tidak lebih dari 5 menit dan untuk pasien baru tidak lebih dari 10 menit.

Lokasi penelitian ini adalah di Klinik Bintang Meditama yang berada di Jl. Raya Batujajar, No. 93, Desa Cimareme, Kecamatan Ngamprah Kabupaten Bandung Barat, 40552 .

\section{HASIL DAN PEMBAHASAN}

\section{A. Hasil Penelitian}

Klinik Bintang Meditama merupakan Klinik swasta yang mempunyai beberapa poli yaitu diantaranya Poli Umum, Poli Gigi, Poli Kebidanan, Poli KIA, Laboratorium dan Instalasi Farmasi, jika pasien akan berobat pada masing-masing poli harus melakukan dahulu registrasi di loket pendaftaran pasien rawat jalan Klinik Bintang Meditama. Pelayanan pendaftaran merupakan salah satu awal pelayanan di Klinik sebelum menuju poli yang dituju. Penelitian ini dilakukan pada Bulan Mei 2021 didapatkan populasi sebanyak 2.300 maka untuk jumlah sampling yang diambil sebanyak 96 pasien yaitu terdiri dari 48 pasien baru dan 48 pasien lama, pada tabel 1 merupakan lama waktu tunggu pasien baru saat dilayani pada loket pendaftaran rawat jalan, berdasarkan hasil penelitian dapat dilihat lama waktu tunggu pendaftaran pasien baru rawat jalan Klinik Bintang Meditama pada tabel di bawah ini :

Tabel 1. Waktu tunggu pasien baru bagian pendaftaran pasien rawat jalan Klinik Bintang Meditama

\begin{tabular}{ccc}
\hline No. & Lama Waktu tunggu & Jumlah Pasien \\
\hline 1 & 09 Menit & 3 \\
\hline 2 & 10 Menit & 13 \\
\hline 3 & 11 Menit & 18 \\
\hline 4 & 12 Menit & 8 \\
\hline 5 & 13 Menit & 1 \\
\hline 6 & 15 Menit & $\mathbf{4 8}$ \\
\hline $\begin{array}{c}\text { Rata-Rata Lama } \\
\text { Waktu Tunggu }\end{array}$ & $\mathbf{1 2}$ Menit & \\
\hline
\end{tabular}

Sumber : Data Primer 2021

Berdasarkan tabel 1 di atas dapat dilihat dari hasil penelitian rata-rata lama waktu tunggu pasien baru selama 12 menit, belum sesuai dengan standar yang ditetapkan oleh Klinik tersebut, rata-rata waktu tunggu pasien baru dapat dikategorikan lambat $(\geq 10$ menit) sebanyak 45 pasien, kategori cepat ( $\leq 10$ menit) sebanyak 3 pasien, penyebab lamanya waktu tunggu untuk pasien baru yaitu pasien lupa membawa kartu identitas seperti KTP sehingga petugas harus melakukan wawancara untuk mengisi rekam medis pasien tersebut.

Tabel 2. Waktu tunggu pasien lama bagian pendaftaran pasien rawat jalan Klinik Bintang Meditama

Evaluasi Spm Lama Waktu Tunggu Pelayanan Pendaftaran Pasien Rawat Jalan di Klinik Bintang Meditama 


\begin{tabular}{ccc}
\hline No. & Lama Waktu Tunggu & Jumlah Pasien \\
\hline 1 & 05 Menit & 6 \\
\hline 2 & 06 Menit & 18 \\
\hline 3 & 07 Menit & 12 \\
\hline 4 & 08 Menit & 5 \\
\hline 5 & 09 Menit & 1 \\
\hline 6 & 10 Menit & 1 \\
\hline 7 & 11 Menit & $\mathbf{4 8}$ \\
\hline Rata-Rata Lama Waktu Tunggu & $\mathbf{0 6}$ Menit & \\
\hline
\end{tabular}

Sumber : Data Primer 2021

Berdasarkan tabel 2 di atas merupakan hasil penelitian lama waktu tunggu pendaftaran pasien lama rawat jalan Klinik Bintang Meditama. Hasil rata-rata lama waktu tunggu pada pasien lama yaitu selama 06 menit dan masih belum sesuai dengan standar pelayanan minimal, rata-rata waktu tunggu pasien lama dapat dikategorikan lambat $(\geq 5$ menit ) sebanyak 48 pasien, penyebab lamanya waktu tunggu pada pasien lama yaitu sering terjadinya jaringan eror pada komputer yang menyebabkan pasien harus menunggu lama, dan kurangnya petugas dalam mencari rekam medis.

\section{B. Pembahasan}

Berdasarkan output penelitian ini dihasilkan bahwa usang saat tunggu pelayanan pendafatran dalam pasien baru pada Klinik Bintang Meditama yaitu 12 mnt sedangkan untuk pasien lama yaitu 06 menit, hasil rata-rata waktu saat petugas melayani pasien baru maupun pasien lama belum sesuai dengan standar pelayanan minimal yang ditetapkan oleh Klinik tersebut. Hal ini sesuai dengan penelitian yang dilakukan oleh (FaikdanFerdiansyah. 2019) Rata-rata waktu yang dibutuhkan untuk pasien baru 12 menit 40 detik sedangkan untuk pasien lama 08 menit 44 detik hal ini disebabkan oleh ketersediaan petugas pada bagian pendaftaran kurang, pasien lupa membawa kartu identitas, komputer eror dan dokumen rekam medis tidak ditemukan pada rak filling, sedangkan berdasarkan penelitian yang dilakukan oleh Henny Maria Ulfa (2017) SDM pada penelitian ini sudah sangat mencukupi, SOP sudah berjalan tapi belum optimal, sarana dan prasarana sudah baik (Ulfa, 2017). Apabila dicermati menurut standar pelayanan minimal yang ditetapkan oleh masingmasing peneliti belum memenuhi standar pelayanan minimal. Dari seluruh sampel yang diteliti hampir semuanya melebihi baku lama waktu tunggu saat pelayanan registrasi rawat jalan. Petugas registrasi wajib menerima training pelayanan secara terpola sebagai akibatnya pengetahuan dan keterampilan pada pelayanan bisa terus ditingkatkan.

\section{KESIMPULAN}

Berdasarkan output penelitian ini dapat disimpulkan lama waktu tunggu pada pelayanan pendaftaran pasien rawat jalan baru yaitu 12 menit dan untuk pasien rawat jalan lama yaitu 06 menit. Hasil ini pertanda bahwa pelayanan pada registrasi pasien rawat jalan pada kategori waktu tunggu belum sinkron menggunakan standar pelayanan minimal yang ditetapkan oleh klinik tersebut. Hasil ini pertanda bahwa pelayanan pada registrasi pasien rawat jalan pada kategori saat tunggu belum sinkron menggunakan baku pelayanan minimal yang ditetapkan sang klinik tersebut, pada pelayanan pasien rawat jalan baru untuk waktu tunggu tidak lebih dari 10 menit dan untuk pasien rawat jalan lama tidak lebih dari 5 menit.

Maka dari itu dengan dilakukanya penelitian ini kita mengetahui lama waktu tunggu pelayanan pendafataran di Klinik Bintang Meditama baik pasien baru juga pasien Evaluasi Spm Lama Waktu Tunggu Pelayanan Pendaftaran Pasien Rawat Jalan di Klinik Bintang Meditama 
lama dengan hasil yang belum memenuhi standar pelayanan minimal, buat itu kita wajib mengevaluasi pelayanan disarankan bagi petugas usahakan lebih memperhatikan lamanya waktu tunggu pada bagian registrasi rawat jalan menggunakan bekerja lebih cepat dan teliti sinkron menggunakan SOP supaya tercapainya pelayanan waktu tunggu registrasi rawat jalan sinkron menggunakan SPM yang telah dipengaruhi oleh Klinik tersebut, memasang template persayaratan pendafatran rawat jalan pada bagian gerbang awal masuk ketika pasien akan berobat, menambah petugas pendafatran yang lebih kompeten dan tak jarang mengikuti training pelayanan secara terpola sebagai akibatnya pengetahuan dan keterampilan pada pelayanan bisa terus ditingkatkan lantaran keterampilan memiliki dampak yang signifikan menggunakan mutu atau kualitas pelayanan, supaya terciptanya pelayanan yang lebih baik.

\section{BIBLIOGRAFI}

Beatson, Josephine, Broadbear, Jillian Helen, Sivakumaran, Hemalatha, George, Kuruvilla, Kotler, Eli, Moss, Francine, \& Rao, Sathya. (2016). Missed diagnosis: The emerging crisis of borderline personality disorder in older people. Australian \& New Zealand Journal of Psychiatry, 50(12), 1139-1145.

Depkes, R. I. (2009). Profil kesehatan indonesia. Jakarta: Depkes RI, 200.

Hafizurrachman. (2004). Pengukuran Kepuasan Suatu Institusi Kesehatan. Majalah Kedokteran Indonesia, 54(7), 283-288.

Hani, Febriyanti Dwi. (2013). Deskripsi Faktor-Faktor Yang Mempengaruhi Waktu Tunggu Pendaftaran di TPPRJ RSUD Tugurejo Semarang Tahun 2003. Journal of Chemical Information and Modeling, 53(9), 1689-1699.

Komalasari, Pitri. (2019). Hubungan Waktu Tunggu Dengan Tingkat Kepuasan Pasien Di Instalasi Gawat Darurat Rumah Sakit Umum Daerah Bayu Asih Purwakarta.

Kusumaningtyas, Dian. (2016). Pengaruh Kualitas Layanan Terhadap Kepuasan Pasien Rawat Inap Pada Rumah Sakit X di Kota Malang. Jurnal NUSAMBA, 1(1), 68-76.

Menkes, R. I. (2011). Peraturan Menteri Kesehatan Republik Indonesia No. 028/MenKes/Per/I/2011 tentang Klinik. Jakarta: Kementrian Kesehatan RI.

Mumu, Like J., Kandou, Grace D., \& Doda, Diana V. (2015). Analisis Faktor-Faktor Yang Berhubungan Dengan Kepuasan Pasien di Poliklinik Penyakit Dalam RSUP Prof . Dr . R . D . Kandou Manado Clinic of Internal Medicine Department of RSUP Prof . Dr . R . D . Kandou. Jurnal Unsrat, 1.

Nurfadillah, Aulia, \& Setiatin, Sali. (2021). Pengaruh Waktu Tunggu Pasien Rawat Jalan Terhadap Kepuasan Pelayanan Pendaftaran di Klinik X Kota Bandung. Cerdika: Jurnal Ilmiah Indonesia, 1(9), 1133-1139.

Permenkes. (2008a). Peraturan Menteri Kesehatan No.269/MENKES/PER/III/2008.

Permenkes, R. I. (2008b). Peraturan Menteri Kesehatan Republik Indonesia No. 269/MenKes/Per/III/2008 tentang Rekam Medis. Jakarta: Kementerian Kesehatan $R I$.

Permenkes, R. I. (2008c). Permenkes Nomor 269/Menkes/Per/III/2008 Tentang Rekam Medis. Jakarta: Kemenkes RI.

RI, Depkes. (2008). Keputusan Menteri Kesehatan Republik Indoneia Nomor. 129 Tahun 2009 Tentang Standar Pelayanan Minimal Rumah Sakit. Jakarta: Kemenkes RI.

Sinadia, Asmiita, Kimbal, Marthen, \& Undap, Gustaf. (2018). Peran Dinas Kesehatandalam Penyediaan Logistik di Puskesmas Kecamatan Manganitu. JURNAL EKSEKUTIF, 1(1).

Tena, Inggrida Sero. (2017). Faktor penyebab lama waktu tunggu di bagian pelayanan rekam medis rawat jalan RSUD Panembahan Senopati Bantul.

Ulfa, Henny Maria. (2017). Standar Pelayanan Minimal Waktu Tunggu di Pendaftaran

Evaluasi Spm Lama Waktu Tunggu Pelayanan Pendaftaran Pasien Rawat Jalan di Klinik Bintang Meditama 
Pasien Rawat Jalan di RSUD Petala Bumi Provinsi Riau. Photon: Jurnal Sain Dan Kesehatan, 8(01), 57-61.

(C) 2021 by the authors. Submitted for possible open access publication under the

(c) (7) (2) terms and conditions of the Creative Commons Attribution (CC BY SA)

c. license (https://creativecommons.org/licenses/by-sa/4.0/). 